\title{
Ki-67 can be used for further classification of triple negative breast cancer into two subtypes with different response and prognosis
}

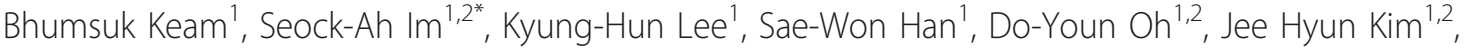 \\ Se-Hoon Lee ${ }^{1,2}$, Wonshik Han ${ }^{2,3}$, Dong-Wan Kim², ${ }^{1,}$ Tae-You Kim ${ }^{1,2}$, In Ae Park ${ }^{2,4}$, Dong-Young Noh ${ }^{2,3}$, \\ Dae Seog Heo ${ }^{1,2}$ and Yung-Jue Bang ${ }^{1,2}$
}

\begin{abstract}
Introduction: Triple negative breast cancer (TNBC) has a poorer survival, despite a higher response rate to neoadjuvant chemotherapy. The purpose of this study was to identify the predictive or prognostic value of Ki-67 among patients with TNBC treated with neoadjuvant chemotherapy, and the role of Ki-67 in further classification of TNBC.

Methods: A total of 105 TNBC patients who received neoadjuvant docetaxel/doxorubicin chemotherapy were included in the present study. Pathologic complete response (pCR) rate, relapse-free survival (RFS), and overall survival (OS) were compared according to the level of Ki-67.

Results: pCR was observed in $13.3 \%$ of patients. TNBC with high Ki-67 expression ( $\geq 10 \%)$ showed a higher pCR rate to neoadjuvant chemotherapy than TNBC with low Ki-67 expression. None of the low Ki-67 group achieved pCR (18.2\% in the high Ki-67 group vs. 0.0\% in the low Ki-67 group, $P=0.019$ ). However, a high Ki-67 expression was significantly associated with poor RFS and OS in TNBC, despite a higher pCR rate $(P=0.005, P=0.019$, respectively). In multivariate analysis, high Ki-67 was an independent prognostic factor for RFS in TNBC (hazard ratio $=7.82, P=$ 0.002). The high Ki-67 group showed a similar pattern of recurrence with overall TNBC, whereas the low Ki-67 group demonstrated a relatively constant hazard rate for relapse.
\end{abstract}

Conclusions: TNBC with high Ki-67 was associated with a more aggressive clinical feature despite a higher pCR rate. High proliferation index Ki-67 can be used for further classification of TNBC into two subtypes with different responses and prognosis.

\section{Introduction}

Triple negative breast cancer (TNBC) demonstrates poor prognosis because of aggressive tumor biology, and lack of targeted agents such as trastuzumab or tamoxifen $[1,2]$. TNBC has a pattern of rapid recurrence following diagnosis, and the peak risk of recurrence is within three years $[3,4]$. However, after the peak risk period, the risk of recurrence declines rapidly, and recurrences seldom occur thereafter $[3,4]$.

Several reports suggested that TNBC was a heterogeneous group comprising subtypes with different clinical

\footnotetext{
* Correspondence: moisa@snu.ac.kr

'Department of Internal Medicine, Seoul National University College of

Medicine, 101 Daehang-ro, Jongno-gu, Seoul, 110-744, Korea

Full list of author information is available at the end of the article
}

outcomes, and further classification of TNBC using cytokeratin (CK) 5/6 and epidermal growth factor receptor (EGFR) was useful to discriminate these subtypes [5-7]. True basal subtype in TNBC, which was defined as CK5/ 6 positive or EGFR positive, has shown poorer survival than CK5/6 and EGFR negative TNBC, which meant that TNBC could be divided into two subtypes: the aggressive clone and the less aggressive clone. New clinically applicable biologic markers for TNBC need to be developed in order to identify the patients with poor prognosis, and alternative treatment options are needed [1].

The proliferation marker Ki-67 has repeatedly been confirmed as an independent predictive and prognostic factor in early breast cancer [8]. Breast cancer with high Ki-67 expression responds better to chemotherapy [9-12], but is

\section{Biomed Central}

(c) 2011 Keam et al.; licensee BioMed Central Ltd. This is an open access article distributed under the terms of the Creative Commons Attribution License (http://creativecommons.org/licenses/by/2.0), which permits unrestricted use, distribution, and reproduction in any medium, provided the original work is properly cited. 
associated with poor prognosis [13-16]. This phenomenon is similar to the triple negative paradox, which denotes that TNBC had a poorer survival, despite a higher response rate to neoadjuvant chemotherapy $[4,10,17]$. In addition, TNBC is associated with a higher expression of Ki-67 than non-TNBC $[10,18]$. However, to date, the reason for the triple negative paradox is not clear, and there is little study focusing on the clinical significance of Ki-67 in TNBC. The purpose of this study was to identify the predictive or prognostic value of Ki-67 among patients with TNBC treated with neoadjuvant chemotherapy, and the role of Ki-67 in further classification of TNBC.

\section{Materials and methods}

\section{Patients and chemotherapy}

Recently, we conducted neoadjuvant docetaxel/doxorubicin chemotherapy in stage II or III breast cancer, and reported the prognostic and predictive role of the molecular markers $[10,19]$. The detailed eligibility criteria and regimen were described in our prior reports $[10,19]$. In brief, the patients received three cycles of neoadjuvant docetaxel/doxorubicin chemotherapy by intravenous infusion every three weeks. After three cycles of neoadjuvant chemotherapy, the patients were re-evaluated for response and underwent curative surgery. Subsequently, the patients received three more cycles of docetaxel/ doxorubicin as an adjuvant chemotherapy, followed by hormonal or radiation therapy, if indicated [20]. Between January 2002 and September 2008, a total of 370 consecutive patients who received neoadjuvant docetaxel/ doxorubicin chemotherapy at Seoul National University Hospital were included in the present study. Among the 370 patients, 109 patients were classified as TNBC. We excluded one patient with metaplastic carcinoma because triple negative phenotype in metaplastic carcinoma showed a different tumor biology than that of invasive ductal carcinoma [21]. Three patients were excluded because Ki-67 was not available due to lack of tissue. Finally, a total of 105 TNBC patients were analyzed. This study protocol was reviewed and approved by the Institutional Review Board of the Seoul National University Hospital (approval number: H-1003-058-313). Because this study was performed using a total of 370 consecutive patients in our database, and involved no more than minimal risk for the subjects, the Institutional Review Board approved our request for the waiver of informed consent. Recommendations of the Declaration of Helsinki for biomedical research involving human subjects were also followed.

\section{Immunohistochemistry}

We performed an immunohistochemistry (IHC) using tissues obtained before treatment. Estrogen receptor (ER), progesterone receptor (PR), human epidermal growth factor receptor 2 (HER2), p53, bcl-2, and Ki-67 expressions were evaluated. IHC was performed as previously described $[14,22]$. ER and PR positivity was defined as $\geq 10 \%$ positive tumor cells with nuclear staining. HER2 positivity was defined as either HER2 gene amplification by fluorescent in situ hybridization or scored as $3+$ by IHC [23]. In case of HER2 2(+), fluorescent in situ hybridization was performed to determine HER2 positivity. TNBC was defined as ER(-), PR(-), and HER2(-), regardless of the expression of EGFR and basal cytokeratins. Only cytoplasmic staining was scored as positive for bcl-2, regardless of the intensity of the stained cells. Cells stained for Ki-67 and p53 were counted and expressed as a percentage. The percentage was determined by the number of Ki-67 positive cells among the total number of counted tumor cells. High expression of $\mathrm{Ki}-67$ was defined as $\geq 10 \%$, because $10 \%$ as cutoff provided the best prognosis-prediction results in our institute [14]. Specimens with no residual invasive carcinoma in the both breast and lymph nodes were classified as pathologic complete response (pCR). Residual ductal carcinoma in situ was also included in the pCR category [24]. Otherwise the specimens which did not achieve pCR category were classified as residual disease

\section{Statistics}

Relapse-free survival (RFS) was determined as the interval between the initiation of neoadjuvant chemotherapy and the date when disease relapse or progression was first documented, or the date of death from any cause. Overall survival (OS) was measured from the date neoadjuvant chemotherapy was initiated to the date of death.

The significance of the difference in the variables among two Ki-67 groups was calculated using Chi-square test or Fisher's exact test, where appropriate. The KaplanMeier product limit method and the Cox proportional hazard regression (PHR) model were used for survival analysis. The multivariate Cox PHR model was used to develop a prediction model for risk of relapse and death. Discrimination for survival data was evaluated using the C statistic with concordance index (C-index) $[25,26]$, which is similar in concept to the area under the receiver operating characteristic (ROC) curve in the logistic model, but is appropriate for censored data. The C-index is the probability that given two subjects, one who will develop an event and the other who will not, the model will assign a higher probability of an event to the former [25]. In general, the model is considered as good for C-index value above 0.75 .

The log-rank tests were used to compare RFS or OS between different groups. Hazard function is the instantaneous failure rate at time $t$, which is the probability of 
event in the next small interval. All statistical tests were two-sided, with the level of significance established at $P<0.05$. Statistical analyses were performed using STATA statistical software version 11.0 (STATA, College Station, TX, USA) and R software version 2.10.1 [27]. $R$ package with theDesign, survivalROC, and survcomp libraries.

\section{Results}

Table 1 shows the baseline characteristics of the 105 patients. pCR was observed in $13.3 \%$ of the patients. With a median follow-up duration of 33.6 months, 33 relapse events occurred, and 20 patients died of disease progression. Estimated one-, two-, and three-year RFS rates, as calculated by the Kaplan-Meier method, were $83.8 \%, 71.6 \%$, and $64.6 \%$, respectively. The median value of Ki-67 was $20.0 \%$ (range $=0.0$ to $80.0 \%$, standard deviation $=23.3$.

\section{Response to neoadjuvant chemotherapy by Ki-67 expression status in TNBC}

Clinicopathologic characteristics between high and low Ki-67 groups were not different (Table 1). However, TNBC with high Ki-67 showed a higher pCR rate to neoadjuvant chemotherapy than TNBC with low Ki-67, and none of the patients in the low Ki-67 group achieved pCR (18.2\% in the high Ki-67 group vs. $0.0 \%$ in the low Ki-67 group, $P=0.019$ ). pCR rate was proportionally associated with the level of Ki-67. When analyzing with a cutoff of $\mathrm{Ki}-67$ quartile $(\mathrm{Q})$, the $\mathrm{pCR}$ rates were $0.0 \%$ in the first $\mathrm{Q}, 14.3 \%$ in the second $\mathrm{Q}, 18.2 \%$ in the third $\mathrm{Q}$, and $22.2 \%$ in the fourth $\mathrm{Q}$, respectively.

\section{Survival by Ki-67 expression status in TNBC}

High Ki-67 expression was significantly associated with poor RFS and OS in TNBC (Figure 1). Combining PCR and Ki-67, residual disease (RD) with high Ki-67 showed poorer RFS than RD with low Ki-67 and pCR with high Ki-67 (Figure 2). RD with low Ki-67 showed better RFS than RD with high Ki-67 $(P=0.017)$. However, there was no statistical difference in RFS between pCR with high Ki67 and RD with low Ki-67 $(P=0.449)$. Univariate analysis revealed that initial clinical stage, pathologic nodal stage, histologic grade, and Ki-67 were prognostic factors in TNBC. However, bcl2 and p53 were not associated with RFS. In multivariate analysis, Ki-67 was the independent prognostic factor for RFS in TNBC (Table 2). High Ki-67 expression was also significantly associated with poorer OS in multivariate analysis as well as univariate analysis (Table S1 in Additional file 1).

The discriminatory ability of the model for RFS was measured using $\mathrm{C}$ statistics. The $\mathrm{C}$-index was 0.83 (95\% confidence interval 0.78 to 0.89 ), indicating good model performance. We examined the hazard function for
Table 1 Baseline characteristics of 105 patients

\begin{tabular}{|c|c|c|c|c|}
\hline Characteristics & $\begin{array}{c}\text { Total } \\
\text { No. of } \mathrm{Pt} \\
(\%)\end{array}$ & $\begin{array}{l}\text { Low Ki-67 } \\
\text { No. of Pt } \\
\text { (\%) }\end{array}$ & $\begin{array}{l}\text { High Ki- } 67^{\mathrm{a}} \\
\text { No. of Pt } \\
(\%)\end{array}$ & $\begin{array}{c}P- \\
\text { value }\end{array}$ \\
\hline \multicolumn{5}{|l|}{ Median age (range) } \\
\hline Age $<35$ years & $18(17.1)$ & $5(17.9)$ & $13(16.9)$ & 0.907 \\
\hline Age $\geq 35$ years & $87(82.9)$ & $23(82.1)$ & $64(83.1)$ & \\
\hline \multicolumn{5}{|l|}{ Performance status } \\
\hline ECOG 0 & $25(23.8)$ & $7(25.0)$ & $18(23.4)$ & 0.686 \\
\hline ECOG 1 & $78(74.3)$ & $21(75.0)$ & $57(74.0)$ & \\
\hline ECOG 2 & $2(1.9)$ & $0(0.0)$ & $2(2.6)$ & \\
\hline \multicolumn{5}{|l|}{$\begin{array}{l}\text { Pathologic } \\
\text { characteristics }\end{array}$} \\
\hline $\begin{array}{l}\text { Invasive ductal } \\
\text { carcinoma }\end{array}$ & $101(96.2)$ & $28(100.0)$ & $73(94.8)$ & 0.572 \\
\hline Others & $4(3.8)$ & $0(0.0)$ & $4(5.2)$ & \\
\hline \multicolumn{5}{|l|}{ Initial clinical stage } \\
\hline$\| A$ & $4(3.8)$ & $1(3.6)$ & $3(3.9)$ & 0.985 \\
\hline$\| B$ & $19(18.1)$ & $5(17.9)$ & $14(18.2)$ & \\
\hline$\| \mathrm{A}$ & $45(42.9)$ & $11(39.3)$ & $34(44.2)$ & \\
\hline$\| \mathrm{II}$ & $18(17.1)$ & $5(17.9)$ & $13(16.9)$ & \\
\hline IIIC & $19(18.1)$ & $6(21.4)$ & $13(16.9)$ & \\
\hline \multicolumn{5}{|l|}{$\begin{array}{l}\text { Inflammatory breast } \\
\text { cancer }\end{array}$} \\
\hline No & $97(92.4)$ & $25(89.3)$ & $72(93.5)$ & 0.437 \\
\hline Yes & $8(7.6)$ & $3(10.7)$ & $5(6.5)$ & \\
\hline \multicolumn{5}{|l|}{ Type of surgery } \\
\hline Breast conserving & $44(41.9)$ & $13(46.4)$ & $31(40.3)$ & 0.571 \\
\hline Mastectomy & $61(58.1)$ & 15 (53.6) & $46(59.7)$ & \\
\hline \multicolumn{5}{|l|}{ Radiation therapy } \\
\hline No & $11(10.5)$ & $2(7.1)$ & $9(11.7)$ & 0.723 \\
\hline Yes & $94(89.5)$ & $26(92.9)$ & $68(88.3)$ & \\
\hline \multicolumn{5}{|l|}{ Nuclear grade } \\
\hline I & $1(1.0)$ & $0(0.0)$ & $1(1.3)$ & 0.260 \\
\hline$\|$ & $7(6.7)$ & $2(7.1)$ & $5(6.5)$ & \\
\hline III & $88(73.3)$ & $24(85.7)$ & $53(68.8)$ & \\
\hline Unknown & $20(19.0)$ & $2(7.1)$ & $18(23.4)$ & \\
\hline \multicolumn{5}{|l|}{ Histologic grade } \\
\hline 1 & $0(0.0)$ & $0(0.0)$ & $0(0.0)$ & 0.097 \\
\hline$\|$ & $23(21.9)$ & $10(35.7)$ & $13(16.9)$ & \\
\hline III & $74(70.5)$ & $17(60.7)$ & $57(74.0)$ & \\
\hline Unknown & $8(7.6)$ & $1(3.6)$ & $7(9.1)$ & \\
\hline \multicolumn{5}{|l|}{ bcl-2 } \\
\hline Negative & $66(62.9)$ & 15 (53.6) & $51(66.2)$ & 0.235 \\
\hline Positive & $39(37.1)$ & $13(46.4)$ & $26(33.8)$ & \\
\hline \multicolumn{5}{|l|}{ p53 } \\
\hline Negative & 39 (37.1) & $12(42.9)$ & $27(35.1)$ & 0.657 \\
\hline Positive & $65(61.9)$ & $16(57.1)$ & 49 (63.6) & \\
\hline Unknown & $1(1.0)$ & $0(0.0)$ & $1(1.3)$ & \\
\hline \multicolumn{5}{|l|}{$\mathrm{pCR}$} \\
\hline No & $91(86.7)$ & $28(100.0)$ & $86(81.8)$ & 0.019 \\
\hline Yes & $14(13.3)$ & $0(0.0)$ & $14(18.2)$ & \\
\hline
\end{tabular}

Abbreviations: ECOG, Eastern Cooperative Oncology Group; $\mathrm{pCR}$, pathologic complete response.

${ }^{a}$ High Ki-67 expression was defined as $\geq 10 \%$. 


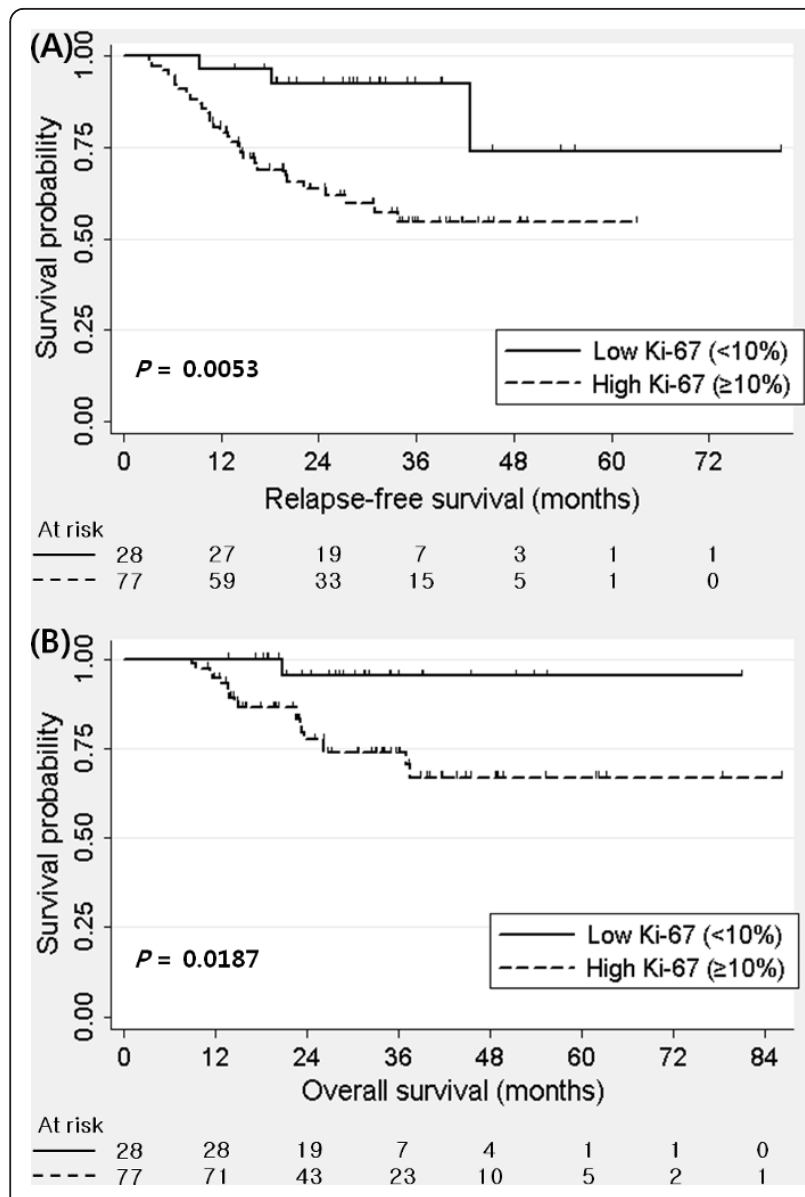

Figure 1 Kaplan-Meier curve of (A) relapse-free survival and (B) overall survival by $\mathrm{Ki}-67$ in triple negative breast cancer.

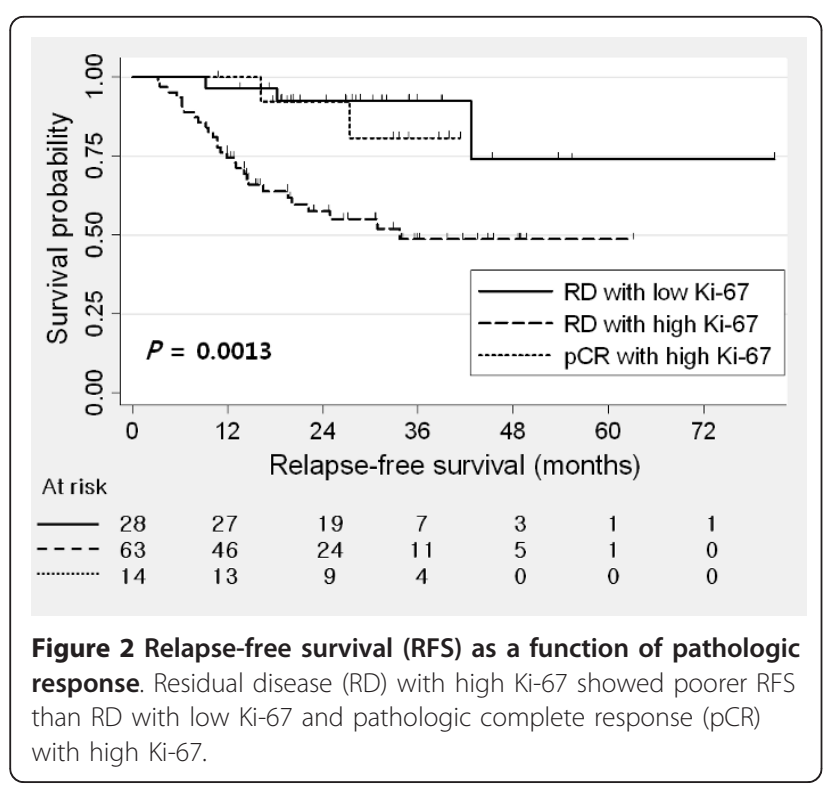

relapse. Figure 3A shows kernel estimates of the hazard functions of relapse in TNBC. TNBC has a pattern of rapid recurrence following diagnosis, and peak risk of recurrence was at 12 months. After three years, relapse did not occur except for one patient. When evaluating the hazard function by Ki-67 expression status, the high Ki-67 group showed a similar pattern of recurrence with overall TNBC, whereas the low Ki-67 group demonstrated a relatively constant hazard rate for relapse (Figure 3B).

\section{Discussion}

In the present study, we found that TNBC with high Ki-67 expression had poorer survival than TNBC with low Ki-67 expression, despite a higher pCR rate. Furthermore, TNBC with high Ki-67 expression showed rapid recurrence within three years, whereas TNBC with low Ki-67 expression showed a near-constant recurrence rate. Ki-67 could divide TNBC into two different clinical subtypes.

It is well confirmed that $\mathrm{pCR}$ to neoadjuvant chemotherapy is an independent prognostic factor for survival [28-30]. However, several studies have shown that TNBC has a higher pCR rate but poorer survival than non-TNBC $[4,10,17]$. Like this triple negative paradox, we found that high Ki-67 in TNBC was associated with a higher pCR rate and poorer survival. High Ki-67, representing high proliferation potential, could explain the paradoxical feature.

Ki-67 is a cell proliferation-associated antigen that is expressed in all stages of the cell proliferative cycle except the G0 (quiescent) phase [31]. Among the proliferation-related markers, Ki-67 is known to be the simplest and a widely used method to assess tumor proliferation. Several studies have investigated the predictive and prognostic values of Ki-67 in breast cancer patients receiving neoadjuvant chemotherapy [9,11,32-39]. High Ki-67 was associated with higher response rate to neoadjuvant chemotherapy in breast cancer $[9,11,34,35,37]$, although no association between high Ki-67 and response rate was also reported $[33,36,39]$. Some studies emphasized the change of Ki-67 or postoperative level of $\mathrm{Ki}-67$ in predicting the response $[9,32,33,37,38]$. Recently, Jones et al. [9] reported that higher pre-treatment Ki-67 was significantly more likely to achieve pCR than lower Ki-67, but was associated with poor RFS and OS. This was consistent with our results. However, the role of Ki-67 is still not yet conclusive because of heterogeneous patient populations, small sample sizes, and different chemotherapeutic regimens in previous studies [9,11,33-39].

Generally, tumor responsiveness to chemotherapy is believed to be associated with longer survival. However, TNBC, which has a higher Ki-67 level than non-TNBC 
Table 2 Univariate and multivariate Cox regression analysis of factors associated with relapse-free survival in triple negative breast cancer

\begin{tabular}{|c|c|c|c|c|c|c|}
\hline \multirow[b]{2}{*}{ Variables } & \multicolumn{3}{|c|}{ Univariate } & \multicolumn{3}{|c|}{ Multivariate } \\
\hline & $\mathrm{HR}$ & $95 \% \mathrm{Cl}$ & $P$-value & HR & $95 \% \mathrm{Cl}$ & $P$-value \\
\hline \multicolumn{7}{|l|}{ Age } \\
\hline$<35$ years & 1 & & & - & & \\
\hline$\geq 35$ years & 0.77 & 0.33 to 1.76 & 0.529 & & & \\
\hline \multicolumn{7}{|l|}{ Performance status } \\
\hline ECOGO & 1 & & & - & & \\
\hline ECOG1 & 1.41 & 0.54 to 3.70 & 0.483 & & & \\
\hline ECOG2 & 4.29 & 0.83 to 22.17 & 0.082 & & & \\
\hline \multicolumn{7}{|l|}{ Initial clinical stage } \\
\hline$\|A\| B$, & 1 & & & 1 & & \\
\hline$\| \mathrm{A}$ & 9.75 & 1.30 to 73.30 & 0.027 & 7.51 & 0.98 to 57.83 & 0.053 \\
\hline$\| \mathrm{II}$ & 9.59 & 1.18 to 77.94 & 0.034 & 7.72 & 0.92 to 64.93 & 0.060 \\
\hline IIIC & 18.59 & 2.37 to 146.04 & 0.005 & 14.75 & 1.74 to 125.11 & 0.014 \\
\hline \multicolumn{7}{|l|}{ Pathologic N stage } \\
\hline pNO & 1 & & & 1 & & \\
\hline pN1 & 3.79 & 1.47 to 9.77 & 0.006 & 5.87 & 2.08 to 16.59 & 0.001 \\
\hline $\mathrm{pN} 2$ & 4.14 & 1.33 to 12.88 & 0.014 & 4.95 & 1.45 to 16.91 & 0.011 \\
\hline pN3 & 6.51 & 2.09 to 20.26 & 0.001 & 7.54 & 2.14 to 26.56 & 0.002 \\
\hline \multicolumn{7}{|l|}{$b c l-2$} \\
\hline Negative & 1 & & & - & & \\
\hline Positive & 0.87 & 0.43 to 1.76 & 0.691 & & & \\
\hline \multicolumn{7}{|l|}{ p53 } \\
\hline Negative & 1 & & & - & & \\
\hline Positive & 1.05 & 0.52 to 2.16 & 0.885 & & & \\
\hline \multicolumn{7}{|l|}{ Histologic grade } \\
\hline$\|$ & 1 & & & 1 & & \\
\hline III & 3.37 & 1.03 to 11.06 & 0.045 & 2.04 & 0.57 to 7.37 & 0.275 \\
\hline \multicolumn{7}{|l|}{ Ki-67 } \\
\hline Low Ki-67 & 1 & & & 1 & & \\
\hline High Ki-67 & 4.64 & 1.41 to 15.22 & 0.011 & 7.82 & 2.18 to 28.13 & 0.002 \\
\hline Continuous $^{a}$ & 1.02 & 1.01 to 1.03 & 0.003 & - & & \\
\hline
\end{tabular}

Abbreviations: $\mathrm{Cl}$, confidence interval; $\mathrm{HR}$, hazard ratio.

${ }^{a}$ Entered as continuous variable.

$[10,18]$ showed a higher $\mathrm{PCR}$ rate with poor survival $[4,10,17]$. Tumor responsiveness might not always affect prolonged survival in a tumor with high Ki-67. We first found this paradoxical feature in TNBC, and our results suggest that further classification using Ki-67 levels might improve the prognostic significance of $\mathrm{pCR}$ in neoadjuvant chemotherapy. Surely, it is not yet certain whether Ki-67 itself is a causable indicator for the triple negative paradox or just a mediator for another unknown factor. Further research to find out direct association is warranted.

Previous reports indicated that TNBC had a pattern of early recurrence within the first three years of follow-up; however, the risk of recurrence significantly decreased thereafter $[3,4]$. Our study confirms these findings. Furthermore, when analyzing hazard rate by Ki-67 status, only TNBC with high Ki-67 demonstrated a pattern of early recurrence, whereas the low Ki-67 subgroup did not show any pattern at all. This suggests that an early recurrence pattern of TNBC is ascribed to the high Ki-67 subgroup which has a high proliferation potential. TNBC seems to be a heterogeneous group with at least two different clinical courses. TNBC with high proliferation potential should be followed-up more frequently within three years, and could be a candidate for additional postoperative treatments with different mechanisms. Additional discriminating markers should be sought to further refine the classification of TNBC.

The present study has some limitations. First, we did not examine basal markers, namely, CK5/6 and EGFR, which are potential classifiers that differentiate TNBC into an aggressive basal clone and a less aggressive 


\section{Additional material}

Additional file 1: Supplementary Table S1. Univariate and multivariate Cox regression analysis of factors associated with overall survival in triple negative breast cancer.

\section{Abbreviations}

C-index: C statistic with concordance index; CK: cytokeratin; EGFR: epidermal growth factor receptor; ER: estrogen receptor; HER2: human epidermal growth factor receptor 2; IHC: immunohistochemistry; OS: overall survival; pCR: pathologic complete response; PHR: proportional hazard regression; PR: progesterone receptor; Q: quartile; RD: residual disease; RFS: relapse-free survival; ROC: receiver operating characteristic; TNBC: triple negative breast cancer.

\section{Acknowledgements}

This study was supported by the SNU Brain Fusion Program and a grant from the Korean Health 21 R\&D Project, Ministry of Health and Welfare, Republic of Korea (0412-CR01-0704-0001). This study was also partly supported by grant no. 03-2010-019 from the SNUH research fund. We also thank 'Professional Editing Services' for English editing.

\section{Author details}

'Department of Internal Medicine, Seoul National University College of Medicine, 101 Daehang-ro, Jongno-gu, Seoul, 110-744, Korea. ${ }^{2}$ Cancer Research Institute, Seoul National University College of Medicine, 101 Daehang-ro, Jongno-gu, Seoul, 110-744, Korea. ${ }^{3}$ Department of Surgery, Seoul National University College of Medicine, 101 Daehang-ro, Jongno-gu, Seoul, 110-744, Korea. ${ }^{4}$ Department of Pathology, Seoul National University College of Medicine, 101 Daehang-ro, Jongno-gu, Seoul, 110-744, Korea.

\section{Authors' contributions}

SAl and BK designed the concept of the study. SAI, SWH, DYO, JHK, SHL, DWK, TYK, DSH and YJB were responsible for provision of study patients and chemotherapy. DYN and WH were responsible for provision of study patients and surgery. IAP was responsible for pathologic examination and immunohistochemistry. BK and KHL were responsible for data gathering, statistical analysis and interpretation. SAI and BK wrote the final manuscript. All authors read and approved the final manuscript.

\section{Competing interests}

non-basal clone $[40,41]$. Further research is needed to determine which will be a better classifier for TNBC among Ki-67 and basal markers. Second, the pCR rate of our study (13.3\%) was relatively lower than that of another study [17]. This was because only three cycles of neoadjuvant chemotherapy were performed and the tumor size was relatively large.

\section{Conclusions}

In conclusion, TNBC with high $\mathrm{Ki}-67$ was associated with a more aggressive clinical feature despite a higher pCR rate. Ki-67 could explain the triple negative paradox, and Ki-67 can be used for further classification of TNBC into two subtypes with different prognosis. Our report suggests that TNBC with residual disease and high Ki-67 expression should be a candidate for additional postoperative treatment such as platinum-based chemotherapy, or clinical trials specifically testing novel therapies in order to improve the outcome for this highrisk group of patients. In addition, TNBC with high Ki-67 should be followed-up more frequently within three years to guard for any recurrence.
The authors declare that they have no competing interests.

Received: 11 September 2010 Revised: 6 February 2011

Accepted: 2 March 2011 Published: 2 March 2011

\section{References}

1. Gluz O, Liedtke C, Gottschalk N, Pusztai L, Nitz U, Harbeck N: Triplenegative breast cancer-current status and future directions. Ann Oncol 2009, 20:1913-1927.

2. Shimizu C, Ando M, Kouno T, Katsumata N, Fujiwara Y: Current trends and controversies over pre-operative chemotherapy for women with operable breast cancer. Jpn J Clin Oncol 2007, 37:1-8.

3. Dent R, Trudeau M, Pritchard Kl, Hanna WM, Kahn HK, Sawka CA, Lickley LA Rawlinson E, Sun P, Narod SA: Triple-negative breast cancer: clinical features and patterns of recurrence. Clin Cancer Res 2007, 13:4429-4434.

4. Liedtke C, Mazouni C, Hess KR, Andre F, Tordai A, Mejia JA, Symmans WF, Gonzalez-Angulo AM, Hennessy B, Green M, et al: Response to neoadjuvant therapy and long-term survival in patients with triplenegative breast cancer. J Clin Oncol 2008, 26:1275-1281.

5. Cheang MC, Voduc D, Bajdik C, Leung S, McKinney S, Chia SK, Perou CM, Nielsen TO: Basal-like breast cancer defined by five biomarkers has superior prognostic value than triple-negative phenotype. Clin Cancer Res 2008, 14:1368-1376.

6. Millar EK, Graham PH, O'Toole SA, McNeil CM, Browne L, Morey AL, Eggleton S, Beretov J, Theocharous C, Capp A, et al: Prediction of local recurrence, distant metastases, and death after breast-conserving therapy in early-stage invasive breast cancer using a five-biomarker panel. J Clin Oncol 2009, 27:4701-4708. 
7. Rakha EA, El-Sayed ME, Green AR, Lee AH, Robertson JF, Ellis IO: Prognostic markers in triple-negative breast cancer. Cancer 2007, 109:25-32.

8. Urruticoechea A, Smith IE, Dowsett M: Proliferation marker Ki-67 in early breast cancer. J Clin Oncol 2005, 23:7212-7220.

9. Jones RL, Salter J, A'Hern R, Nerurkar A, Parton M, Reis-Filho JS, Smith IE, Dowsett M: Relationship between oestrogen receptor status and proliferation in predicting response and long-term outcome to neoadjuvant chemotherapy for breast cancer. Breast Cancer Res Treat 2010, 119:315-323.

10. Keam B, Im SA, Kim HJ, Oh DY, Kim JH, Lee SH, Chie EK, Han W, Kim DW, Moon WK, et al: Prognostic impact of clinicopathologic parameters in stage II/III breast cancer treated with neoadjuvant docetaxel and doxorubicin chemotherapy: paradoxical features of the triple negative breast cancer. BMC Cancer 2007, 7:203.

11. Petit T, Wilt M, Velten M, Millon R, Rodier JF, Borel C, Mors R, Haegele P, Eber M, Ghnassia JP: Comparative value of tumour grade, hormonal receptors, Ki-67, HER-2 and topoisomerase II alpha status as predictive markers in breast cancer patients treated with neoadjuvant anthracycline-based chemotherapy. Eur J Cancer 2004, 40:205-211.

12. Pohl G, Rudas M, Taucher S, Stranzl T, Steger GG, Jakesz R, Pirker R, Filipits $M$ : Expression of cell cycle regulatory proteins in breast carcinomas before and after preoperative chemotherapy. Breast Cancer Res Treat 2003, 78:97-103.

13. Brown RW, Allred CD, Clark GM, Osborne CK, Hilsenbeck SG: Prognostic value of $\mathrm{Ki}-67$ compared to S-phase fraction in axillary node-negative breast cancer. Clin Cancer Res 1996, 2:585-592

14. Jung SY, Han W, Lee JW, Ko E, Kim E, Yu JH, Moon HG, Park IA, Oh DY, Im SA, et al: Ki-67 expression gives additional prognostic information on St. Gallen 2007 and Adjuvant! Online risk categories in early breast cancer. Ann Surg Oncol 2009, 16:1112-1121.

15. Weikel W, Beck T, Mitze M, Knapstein PG: Immunohistochemical evaluation of growth fractions in human breast cancers using monoclonal antibody Ki-67. Breast Cancer Res Treat 1991, 18:149-154.

16. Weikel W, Brumm C, Wilkens C, Beck T, Knapstein PG: Growth fractions (Ki67) in primary breast cancers, with particular reference to node-negative tumors. Cancer Detect Prev 1995, 19:446-450.

17. Carey LA, Dees EC, Sawyer L, Gatti L, Moore DT, Collichio F, Ollila DW, Sartor $\mathrm{Cl}$, Graham ML, Perou CM: The triple negative paradox: primary tumor chemosensitivity of breast cancer subtypes. Clin Cancer Res 2007 13:2329-2334.

18. Rhee J, Han SW, Oh DY, Kim JH, Im SA, Han W, Park IA, Noh DY, Bang YJ, Kim TY: The clinicopathologic characteristics and prognostic significance of triple-negativity in node-negative breast cancer. BMC Cancer 2008, 8:307.

19. Keam B, Im SA, Kim HJ, Oh DY, Kim JH, Lee SH, Chie EK, Han W, Kim DW, Cho $\mathrm{N}$, et al: Clinical significance of axillary nodal ratio in stage II/III breast cancer treated with neoadjuvant chemotherapy. Breast Cancer Res Treat 2009, 116:153-160.

20. Recht A, Edge SB, Solin LJ, Robinson DS, Estabrook A, Fine RE, Fleming GF, Formenti S, Hudis C, Kirshner JJ, et al: Postmastectomy radiotherapy: clinical practice guidelines of the American Society of Clinical Oncology. J Clin Oncol 2001, 19:1539-1569.

21. Lim KH, Oh DY, Chie EK, Han W, Im SA, Kim TY, Park IA, Noh DY, Ha SW, Bang YJ: Metaplastic Breast Carcinoma: Clinicopathologic Features and Prognostic Value of Triple Negativity. Jpn J Clin Oncol 2009.

22. Lee KH, Im SA, Oh DY, Lee SH, Chie EK, Han W, Kim DW, Kim TY, Park IA Noh DY, et al: Prognostic significance of bcl-2 expression in stage III breast cancer patients who had received doxorubicin and cyclophosphamide followed by paclitaxel as adjuvant chemotherapy. BMC Cancer 2007, 7:63.

23. Perez EA, Roche PC, Jenkins RB, Reynolds CA, Halling KC, Ingle JN, Wold LE: HER2 testing in patients with breast cancer: poor correlation between weak positivity by immunohistochemistry and gene amplification by fluorescence in situ hybridization. Mayo Clin Proc 2002, 77:148-154.

24. Mazouni C, Peintinger F, Wan-Kau S, Andre F, Gonzalez-Angulo AM, Symmans WF, Meric-Bernstam F, Valero V, Hortobagyi GN, Pusztai L: Residual ductal carcinoma in situ in patients with complete eradication of invasive breast cancer after neoadjuvant chemotherapy does not adversely affect patient outcome. J Clin Oncol 2007, 25:2650-2655.

25. Harrell FE Jr, Lee KL, Mark DB: Multivariable prognostic models: issues in developing models, evaluating assumptions and adequacy, and measuring and reducing errors. Stat Med 1996, 15:361-387.
26. Pencina MJ, D'Agostino RB: Overall $C$ as a measure of discrimination in survival analysis: model specific population value and confidence interval estimation. Stat Med 2004, 23:2109-2123.

27. The R Project for Statistical Computing. [http://www.r-project.org/]

28. Fisher B, Bryant J, Wolmark N, Mamounas E, Brown A, Fisher ER, Wickerham DL, Begovic M, DeCillis A, Robidoux A, et al: Effect of preoperative chemotherapy on the outcome of women with operable breast cancer. J Clin Oncol 1998, 16:2672-2685.

29. Kuerer HM, Newman LA, Smith TL, Ames FC, Hunt KK, Dhingra K Theriault RL, Singh G, Binkley SM, Sneige N, et al: Clinical course of breast cancer patients with complete pathologic primary tumor and axillary lymph node response to doxorubicin-based neoadjuvant chemotherapy. J Clin Oncol 1999, 17:460-469.

30. van der Hage JA, van de Velde CJ, Julien JP, Tubiana-Hulin M, Vandervelden C, Duchateau L: Preoperative chemotherapy in primary operable breast cancer: results from the European Organization for Research and Treatment of Cancer trial 10902. J Clin Oncol 2001, 19:4224-4237.

31. Gerdes J, Li L, Schlueter C, Duchrow M, Wohlenberg C, Gerlach C, Stahmer I, Kloth S, Brandt E, Flad HD: Immunobiochemical and molecular biologic characterization of the cell proliferation-associated nuclear antigen that is defined by monoclonal antibody Ki-67. Am J Pathol 1991, 138:867-873.

32. Billgren AM, Rutqvist LE, Tani E, Wilking N, Fornander T, Skoog L: Proliferating fraction during neoadjuvant chemotherapy of primary breast cancer in relation to objective local response and relapse-free survival. Acta Oncol 1999, 38:597-601.

33. Burcombe RJ, Makris A, Richman PI, Daley FM, Noble S, Pittam M, Wright D, Allen SA, Dove J, Wilson GD: Evaluation of ER, PgR, HER-2 and Ki-67 as predictors of response to neoadjuvant anthracycline chemotherapy for operable breast cancer. Br J Cancer 2005, 92:147-155.

34. Colleoni M, Viale G, Zahrieh D, Bottiglieri L, Gelber RD, Veronesi $P$, Balduzzi A, Torrisi R, Luini A, Intra M, et al: Expression of ER, PgR, HER1, HER2, and response: a study of preoperative chemotherapy. Ann Oncol 2008, 19:465-472.

35. Faneyte IF, Schrama JG, Peterse JL, Remijnse PL, Rodenhuis S, van de Vijver MJ: Breast cancer response to neoadjuvant chemotherapy: predictive markers and relation with outcome. $\mathrm{Br} J$ Cancer 2003, 88:406-412.

36. Guarneri V, Piacentini F, Ficarra G, Frassoldati A, D'Amico R, Giovannelli S, Maiorana $A$, Jovic $G$, Conte $P$ : A prognostic model based on nodal status and $\mathrm{Ki}-67$ predicts the risk of recurrence and death in breast cancer patients with residual disease after preoperative chemotherapy. Ann Oncol 2009, 20:1193-1198.

37. Jones RL, Salter J, A'Hern R, Nerurkar A, Parton M, Reis-Filho JS, Smith IE, Dowsett M: The prognostic significance of Ki67 before and after neoadjuvant chemotherapy in breast cancer. Breast Cancer Res Treat 2009, 116:53-68

38. Lee J, Im YH, Lee SH, Cho EY, Choi YL, Ko YH, Kim JH, Nam SJ, Kim HJ, Ahn JS, et al: Evaluation of ER and Ki-67 proliferation index as prognostic factors for survival following neoadjuvant chemotherapy with doxorubicin/docetaxel for locally advanced breast cancer. Cancer Chemother Pharmacol 2008, 61:569-577.

39. von Minckwitz G, Sinn HP, Raab G, Loibl S, Blohmer JU, Eidtmann H, Hilfrich J, Merkle E, Jackisch C, Costa SD, et al: Clinical response after two cycles compared to HER2, Ki-67, p53, and bcl-2 in independently predicting a pathological complete response after preoperative chemotherapy in patients with operable carcinoma of the breast. Breast Cancer Res 2008, 10:R30.

40. Rakha EA, El-Rehim DA, Paish C, Green AR, Lee AH, Robertson JF, Blamey RW, Macmillan D, Ellis IO: Basal phenotype identifies a poor prognostic subgroup of breast cancer of clinical importance. Eur J Cancer 2006, 42:3149-3156.

41. Yamamoto $Y$, Ibusuki M, Nakano M, Kawasoe $T$, Hiki R, Iwase H: Clinical significance of basal-like subtype in triple-negative breast cancer. Breast Cancer 2009, 16:260-267.

doi:10.1186/bcr2834

Cite this article as: Keam et al: Ki-67 can be used for further

classification of triple negative breast cancer into two subtypes with different response and prognosis. Breast Cancer Research 2011 13:R22. 